\title{
Technological Stressors in Developing Countries
}

\author{
Ayodeji Akinlolu Agboola, Omoneye Olufunke Olasanmi* \\ Department of Management and Accounting, Obafemi Awolowo University, Ile-Ife, Nigeria \\ Email: "neyeolasanmi@yahoo.com
}

Received 29 February 2016; accepted 23 April 2016; published 26 April 2016

Copyright $@ 2016$ by authors and Scientific Research Publishing Inc.

This work is licensed under the Creative Commons Attribution International License (CC BY). http://creativecommons.org/licenses/by/4.0/

c) (i) Open Access

\begin{abstract}
Stress as a state of anxiety is produced when responsibilities do not match expected knowledge, and hence challenges one's coping abilities. Job stress can be as a result of the nature of the job (work) or can result from the workers commonly referred to as dispositional stress. Stressors are conditions or situations which trigger stress response. Stressors can be inherent in the job due to factors affecting the occupation. This paper therefore highlights impact of technological stress (technostress) in auditing firm in developing countries.
\end{abstract}

\section{Keywords}

Stress, Stressors, Auditing, Ergonomic Hazards, Management, Performance

\section{Introduction}

Stress is the response of the body to any demand or pressure placed upon it, whether that demand (or pressure) produces pleasure or pain. It is a state of anxiety produced when responsibilities do not match expected knowledge, and hence challenges one's coping abilities. Excessive pressure within an organisation leads to stress. Different definitions of workplace stress have been given by different stress researchers. According to [1] stress not only affects individuals, but also influences their work efficiency and relationships with others, simply defined as the lack of fit between the person and his or her environment [2]. Hence, it is interrelated between an individual and his/her work environment [3]. It is a reaction to imbalance perceived between a person and the environment [4]. Additionally, it could be defined as the pressure or anguish resulting from difficult situations [5]. In 2005, Kavanagh defined stress as a non-specific response of the body to a stimulus or event. In a study by [6], it was observed that stress impacted both positively and negatively [7]. In spite of these different definitions of stress, the fact remains that stress is triggered by an action or a demand. Stress has been discovered to be sub-

"Corresponding author. 
jective and people react to it in different ways [1]. Some people make up their minds to cope with it, especially, if it is constantly associated with a job description; some tolerate it while others always try to avoid it if possible. Some individuals break down at the slightest occurrence of stress, while others will not give their best in the absence of stress. Much of a person's reaction depends on the situation and their skills in prevention and reduction [8].

Stressors are conditions or situations which trigger a stress response. Simply put, stressors cause stress. These conditions or situations are perceived as threats or challenges to the individual and can be either physical or psychological. On job, stress could be as a result of work environment also known as organizational or situational stress or characteristics of the workers themselves, known as dispositional stress [9].

\section{Statement of the Problem}

People are spending increasingly more and more time connected to their computers. As computers and technology become ubiquitous throughout modern society, the physical and psychological effects of technology become more apparent in its users. The combination of intensive technology use and work demands has resulted in an increase in computer-related illnesses. The negative effects of computer and technology use have been studied in many fields, and have resulted in the identification of technostress as a documented human reaction to continued interaction with technology [10]. Auditors play a boundary-spanning role [11] and a boundary-spanner requires extensive "interactions with many people, both inside and outside the organization, with diverse needs and expectation" [12]. In order to satisfy the demands of people in their work environment, auditors could be faced with potentially stressful situations [12] [13]. As a boundary-spanner, the auditor interacts with internal staff (team members, supervisor, manager) and external parties (clients, regulators), who are subject to unforeseen problems in their work environment, which could all contribute to higher level of work related stress [14].

Auditors are exposed to a number of stressors in the workplace [15] and it has been discovered that technology is a major stressor [16]-[18]. Auditors experience stress due to high work demands of the profession, both in terms of quantity of the work [19] [20] and the need to meet tight deadlines or budgets which has been enhanced by the ubiquitous nature of technological tools. Hence, this study seeks to examine types of stressors, with particular reference to technostress, and the ergonomic hazards which could arise as a result of technostress.

\section{Related Studies Developing Countries}

[21] published a stress-related study applied to individuals working in computer-related fields. In their survey, a large majority of the respondents agreed with the statements that changes in computer technology creates pressure. The authors concluded that "the men and women who plan, design, and monitor these systems have experienced greater technostress in their jobs and environments and that such technostress is not at all likely to disappear in the foreseeable future".

[22] investigated the effect of technological change in community college libraries and learning resources personnel, with the intention of finding out how employees in Florida community college library and learning resource centers in the USA were dealing with technostress as a result of technological changes in their work environment. Most of the employees sampled believed that technology had made their work "neither less nor more stressful" although they confirmed that technology has increased their workload and added more responsibilities. Employees for whom technology had impacted health negatively were also in the minority. The results of the investigation indicated that the staff reacted positively to technostress and ergonomics. It was thus concluded that technostress and ergonomics on a job can be increased when workers have too little training on the technology adopted on the job, when there is a rapid rate of change in technological innovations, and when there is unrealistic pressure to produce results. [23] studied technostress in the electronic workplace, with the intention of showing whether it affects organisational costs. He discovered that if technostress is not well handled by an organisation, it will lead to lost productivity, absenteeism, accidents, employee turnover, medical fees, and compensation awards to employees who are technostressed. It was revealed that an organisation will continue to lose money due to technostress related cost factors while absenteeism and employee turnover will continue to grow. Moreover, the total cost of workers' compensation claims will also be on the rise as a result of ergonomic hazards sustained by workers on the job. He concluded that organisations have the need to develop technostress reduction training programs in order to reduce the cost associated with technostress which could hamper organisational productivity. 
In a study of Chinese employees, [20] found that technostress affected productivity in different ways despite the potential benefits of using Internet-based and other computer technologies. It was found that greater workload increased technostress thereby making Chinese employees have a feeling of frustration and depression in their struggle to adapt to rapidly advancing and increasingly complex technologies. Unlike the findings obtained in similar studies in the developed countries, the overall technostress level had no significant effect on Chinese employee productivity. However, it was discovered that some individual components of technostress had significant effect on productivity; techno-overload had a significant positive effect on productivity while technoinvasion and techno-insecurity significantly hurt individual productivity. It was observed that using new technologies pushed employees to work faster and be more productive since the culture of the Chinese support employees to endure work overload rather than quit their jobs. However, extremely high workload inevitably overwhelms employees' personal lives and hence, individual productivity is hampered. [19] explored the impact of technostress on productivity in two government organisations in the USA. It was discovered that there were five technostress creators which were techno-overload, techno-invasion, techno-complexity, techno-insecurity and techno-uncertainty, and all these had significant negative impact on individual productivity. This finding is also supported by [21] who studied technostress in the electronic workplace. [24] conducted a study to explore the effect which technology had on librarians working in academic and research libraries in Kuwait. The study set to find out how technology affected management issues, personnel changes, stress sources and performance. It was discovered that the librarians acknowledged an improved performance with the use of technology in spite of the stress and pressure of expanded workload when it was used by non-technically oriented professionals. It was thus concluded that the level of stress associated with technology use could be increased by insufficient formal training programs and inadequate technical support resulting in the majority of librarians becoming frustrated by technological breakdowns.

[21] studied how end-user individual characteristics can affect technostress. The characteristics examined were confidence in using computers, computer literacy, and experience in using computers. It was discovered that a higher value of these characteristics largely led to lower technostress. They found out that individuals who were more confident in using computers and those who were highly literate in its usage were less prone to experiencing technostress. They ascertained that individuals with better experience in computers had less technoinvasion (which is the effect of ICT in creating situations where users can potentially be reached anytime, employee being constantly connected, and a blurring between personal and work-related issues), techno-insecurity (which is a situation where users feel threatened about losing their jobs as a result of newly acquired ICT facilities) and techno-complexity (a situation where the complexity associated with ICT makes a user feel inadequate as far as their skills are concerned and forces them to spend time and effort in learning and understanding various aspects of ICT). The study concluded that task-related confidence can be developed through training in how to perform specific tasks and exposure to repeated instances in which the task is performed. Furthermore, it was concluded that organisations should institute mechanisms to increase overall computer literacy among employees by exposing them to various ICT facilities.

[25] examined the relationship of information-induced stress in terms of mental workload and automation malfunction detection performance in a highly computer-aided task scenario. The study concluded that modern information technology puts hard pressures on individuals' resources by demanding constant refreshing of skills which could lead to ergonomic problems. [21] studied the consequences of technostress for end-users of ICTs in five organizations (two governments, one manufacturing, and two financial). It was observed that socio demographic factors influenced technostress. The results further showed that males experienced more technostress than females (which was somewhat contrary to previous researches) and that technostress decreased as age, education, and computer confidence increased. In this context, past researches indicated that for women, greater autonomy ameliorates the negative effects of work overload associated with IT innovations [26]. With respect to age, it was expected that it would not affect technostress, whereas the findings showed that older people experienced less technostress.

[27] carried out a study to explore the relationship between perceived-job-stress (a measure of technostress) and employee loyalty of Information System and Technology (IS \& T) workers in the United States Midwest. The sample consisted of individuals from 18 different industry sectors which included manufacturing firms, accounting-consulting firms, and general software consulting/developers.

[28] set out to identify the impact of technostress on end-user satisfaction and performance in two publicsector organizations in the mid-western region of the United States. 
[29] conducted a study to examine the factors which could aid in alleviating ergonomic hazards and technostress associated with the adoption of ICT among staff and students of the University of Botswana, South Africa. It was discovered that the rate of ICT adoption in the university was very high because most of their daily routines were accomplished through the use of computers. In spite of the high rate of ICT adoption however, the ICT facilities were not designed to match the standard expected to facilitate functionality within the university. This resulted in technostress which manifested in several ergonomic hazards such as pains in the back, shoulder, fingers, arms, \& neck, and headache. It was thus concluded that training students and administrative staff of the university on the proper use of computers at the workplace will go a long way to alleviate technostress and ergonomic hazards.

[30] carried out a study on the effects of technostress on the continuous use of smart phones among office workers in Seoul Metropolitan area, South Korea. It was discovered that the complexity of smart phones showed an extremely high level of influence on technostress and as a result, people tend to use them as ordinary cellular phones for voice communication, instead of using the various functions they provided. It was thus concluded that technostress could be reduced if continuous education for the utilization of a smart phone is provided by its manufacturing company in order to keep users abreast with trends in the IT world.

[31] carried out a research on the role of technostress in human productivity on the personnel of some IT organisations in Indian. This was achieved by investigating the impact of organisational centralization and technological innovations on the level of technostress experienced by workers within the organisations of interest. The findings of the study indicated an elevating level of technostress which always disrupted individual goals. This was also supported by the conclusions of the studies carried out by [1]. The researchers concluded that technostress was on the rise and can appear in form of ergonomic hazards.

[32] investigated level of technostress on social media users in Turkey. Social network users were chosen based on their usage of information and communication technologies intensively. [20] in a study examined the creators, outcomes, and inhibitors of technostress among Information System users in two government organizations in the United States. It was discovered that five conditions created technostress among the workers. These are techno-overload, techno-invasion, techno-complexity, techno-insecurity, and techno-uncertainty. The outcomes of technostress included role overload, increased role conflict, reduced job satisfaction, decreased innovation while using IS, reduced productivity and reduced commitment of professionals to their current organizations' goals and values. It was concluded that technostress could be reduced by providing the needed literacy support through training in the use of IS facilities, provision of technical support, mechanisms, facilitation of technology involvement to keep IS users informed and familiar with new IS, and provision of mechanisms to help IS users learn about and accept IS-driven changes in their routines and tasks.

[33] evaluated the evolution of technostress as a result of technological change in libraries in India. They found that in as much as technological revolution has allowed work to be carried out faster and more efficient, many employees were not comfortable with the implementation of technology as it involved change and uncertainty, and given the fact that they experienced additional stress known as technostress which may have negative consequences in the organisation. The main finding in this study was that computer use might contribute unhealthy impact, particularly stress. It was thus concluded that employers and organizations concerned have to handle technostress seriously by providing training to members of staff equipped with ICT exploration.

In a different direction to what obtains in most studies relating to technostress, [34] decided to investigate the factor that can affect technostress itself among working individuals who use technology for their work-related tasks. The research focused on studying the impact of information overload and task-technology fit on technostress. The results obtained indicated that information overload increased technostress, whereas task-technology fit led to lower levels of technostress. It was concluded that ICTs could lead to situations of information overload in work settings and hence, organizations need to provide tools for individuals to deal with information overload. This could occur in terms of training interventions for individuals and/or development and use of ICTs that enable individuals to deal with information overload.

\section{Related Studies in Nigeria}

Studies relating to technostress in Nigeria have been fairly limited. [35] studied technostress among librarians in Nigerian universities. They sought to find out the causes, symptoms (ergonomic hazards) and coping strategies. It was discovered that the quick pace of technological change was the major causes of technostress among li- 
brarians. Other causes identified included lack of proper training on the use of technology, poor users interface, and lack of technical support among others. Some of the findings of this study corroborated with those by [35]-[38], who also observed rapid rate of change in technology as a cause/source of technostress in libraries. Several ergonomic hazards of technostress were experienced by librarians. It was discovered that muscle tension was the major hazard of technostress among librarians; other included rapid heartbeat, frustration, negative attitude towards computer, shaky hands and irritable anger. In order to reduce these hazards, some coping strategies were suggested which included buying more adequate user-friendly hardware and software, taking frequent breaks while using a computer, discussing technostress among employee and planning adequately for it.

[39] studied the attitudes of librarians in some selected Nigerian universities toward the use of ICT and found out that training and knowledge are the sine qua non of a positive attitude toward ICT. They concluded that it was essential for librarians to keep up with ICT developments and that training is the first step, which will reduce fear when implementation of ICT begins.

[40] examined the impact of job stress on managers' performance and the findings showed that job stress brought about subjective effects such as fear, anger and anxiety among Nigerian managers, thus resulting in poor concentration, mental block and poor decision making skills. [41] studied the impact of technostress on librarians at Covenant University library, Nigeria.

[42] assessed the symptoms and manifestations of technostress among workers in an open and distance learning institution in Nigeria. The study was carried out to determine the levels of technostress among academic and administrative staff, to ascertain the influence of age and gender on manifestations of technostress and to inquire the relationship between computer hassles and stress manifestations. It was discovered that academic staff and older respondents manifested significantly higher levels of technostress than non-academic staff and younger respondents manifested higher levels of technostress than younger respondents. No significant differences were obtained for male and female participants on technostress manifestations and a positive correlation was observed between computer hassles and stress reaction. This showed that those subjected to high level of technostress are prone to stress-related ergonomic hazards. Such hazards included lowered body immunity, backache, neck ache, tiredness and sleep problems. Others are hypertension, headaches, dizziness, poor appetite, asthma, gastrointestinal disorders, skin rashes, blurred vision, emotional outburst and interpersonal difficulties.

[43] carried out a study involving 646 library personnel from federal universities in Nigeria. Results of the study revealed that respondents are moderately affected by technostress. In spite of the considerable afore discussed technostress-ergonomic hazards-performance empirical literatures, specific studies of these variables as applied to auditing fields are limited in the developing countries.

\section{Types of Stressors}

\subsection{Organizational Stressors}

Organizational Structural Factors: Structural factors such as poor reward systems, lack of freedom or even lack of clear career path, may all bring about stress [44] [45].

Environmental Factors: Changes in the business cycle create economic uncertainties which may lead to stress as people become increasingly anxious about their security [44] [45].

Interpersonal Stress: Organizational politics and struggles over power can also be important sources of stress in the workplace [46].

Organizational Change: A change of any nature may cause stress to occur within an organisation, since most workers would have been used to a stable work environment which could generally be comforting and reassuring. Some common change situations which may lead to job stress include companywide reorganizations, mergers or acquisitions, changes in company policy, managerial or personnel changes [47]-[50].

\subsection{Dispositional Stressors}

These are stressors arising from the individual characteristics of the workers themselves. These include the "Type A Personality" or "Type A Behavioural Pattern" which research has shown is characterized by excessive drive and competitiveness, a sense of urgency, impatience and underlying hostility [51] [52]. Workers with this personality type have been found to experience or report higher stress than other personality types under the same workload [53]-[55]. 


\section{Technostress}

Information technology may have revolutionized modern day life, but it has also brought with it new problems. Technological facilities are supposed to be time-saving devices that make work and life generally, easier and convenient. However, these gadgets have been associated with a form of stress known as Technostress. Technostress is especially likely to occur when new technologies are being introduced, dispersed or adopted by individuals or organisations. Individuals and organisations as a whole are expected to do more in less time because the technology to do so is available. For some people, there is a sense of information overload and finally an inability to cope with all of these ever-changing new technologies. Some researchers [20] [23] [25] believe that technostress as a result of ICTs is on the rise leading to such negative organizational consequences as turnover and productivity losses, while some [56] [57] have actually found out that these technologies have impacted positively on organizational performance.

Technostress simply means technological stress. The name is derived from "technology" and "stress". It is stress experienced by individuals who make use of technologies and computers on a regular basis. It occurs when technological/computer tasks exceed an individual's coping strategies. Technostress has been considered to be a problem, a very real problem [58]. The concept technostress was introduced in 1984 by Bord. [59] coined the term "technostress" and defined it as "a modern disease of adaptation caused by an inability to cope with the new computer technologies in a healthy manner. It manifests itself in two distinct and related ways: in the struggle to accept computer technology, and in the more specialized form of over-identification with computer technology. As a result, he is either struggling to accept computer technology or being over identified with computer technology".

However, some major criticisms of Brod's view is that he regarded technostress as a "condition", a "disease", and the fact that it is caused by "inability" on the part of some individual to cope with it. [60] stated that the information age is all about change, or to be more specific, a response to "techno-change", not about technical components such as machines, programs, network, or fibre optics. This view was supported by [61], who were of the opinion that technology is not to be blamed because computer and technologies are just tools. They opined that since the introduction of technology will involve change, and that such change will eventually lead to some resistance, stress is a natural reaction. Hence, they argued that managing technostress means managing the change involved and not managing the technology itself. [62] viewed technostress not actually as a disease, but as a negative psychological, behavioural, and physiological impact caused, either directly or indirectly, by technology. Technostress has also been proposed as a term which describes the physiological arousal and mental state observed in some people who rely greatly on computers in their work [63]. [45] argued that Brod's definition is only valid from a clinical point of view and that individuals have been able to adapt, cope and even flourish in an automated environment. She opined that Brod's definition of technostress, though accurate to be termed a clinical condition worthy of serious attention, is a very serious problem which misses out many social and environmental factors attached to it. She thus defined technostress as "a condition resulting from having to adapt to the introduction and operation of new technology, particularly when equipment, support, or the technology itself is inadequate".

From all these definitions, it can be rightfully concluded that technostress is another word for technology-related stress. In this context, according to [64], it is stress caused by working with multiple and rapidly changing technologies, and mediating between these systems and the demands of an organization, staff, customers, and personal life. [65] claims that technostress is becoming one of the setbacks of technology. It is experienced by both the young and old and therefore affects individual and organisation [66] [67]. All these could affect an organization by increasing absenteeism, decreasing commitment to work, increasing staff turn-over, increasing complaints from clients and customers, increasing unsafe working practices, adversely affecting staff recruitment, and damaging an organization's image both among its workers and externally [68].

\section{Causes of Technostress}

Technostress can be caused by different technological factors or concerns. According to [68], five of these factors are empirically validated techno stress indicators/creators and they are techno-overload, techno-invasion, techno-complexity, techno-insecurity, techno-uncertainty. Others according to include inappropriate training and lack of standardization within technologies. Techno-overload describes a situation where use of information communication technologies (ICTs) force individuals or professionals to work more, faster, and requires them to 
be more productive. Increased workload with the advent of new technology is not often planned since collections of data and reports can be made available at the click of a button. The pace of work thus becomes faster, and it continues to rise up at a faster speed. This sometimes frustrates an individual's trying to cope. There is no doubting the fact that mobile computing devices make it possible to process real-time information, but this often results in information overload, interruptions, and multi-tasking, which, according to [68], can to lead to "information fatigue" since it expose users to more information. Multitasking implies professionals simultaneously working on different applications and tasks, trying to do more in less time, and experiencing tension. Moreover, work is very often interrupted with e-mails, text messages and office correspondence, which arrive at a fast rate than individuals can cope with. All these put more pressure on users, making them to attend to information as soon as it arrives, creating anxiety, tension and workflows disconnects, and making sustained mental attention difficult. Techno-invasion simply describes a situation in which employees must be constantly available 24/7 since the technology is also available. It is a situation where professionals can potentially be reached anywhere and anytime and feel the need to be constantly connected, even when they are on leave or vacation. With the advent of ICTs, virtually almost all office work can be done online while the employee is as easily accessible as the information. The problem is that an employee's day is constantly interrupted. This often leads to an experience of intrusion on personal time and space, hence, they experience frustration and stress.

Techno-complexity, according to [69] describes a situation in which users of ICT feels incompetent at handling and using new technologies as a result of the complexity associated with it. As employees begin to learn how to operate and work with a device newly introduced within the organization, a new one enters the scene. This new device is often considered to be faster, smarter, and usually smaller than the previous one.

Techno-insecurity is a circumstance which arises when users feel threatened about losing their jobs to other people who have a better understanding of new ICT facilities. This is actually very common among older employees who often feel that younger recruits are more confident in their use of technological facilities and fear that this might force management to question their technical competence. This often leads to tension and stress. An employee's perhaps legitimate concern that some machine will make him or her obsolete is a leading, underlying cause of techno stress. Techno-uncertainty refers to situations where continued changes and upgrades to ICT equipment do not give employees a chance to develop a base of experience for a particular application or system. The rate at which they have to update their knowledge of new facilities keeps increasing. Thus, employees are forced to change their work habits, learn and educate themselves about new ICTs, and strive to always fit into the new technology. There is also the constant pressure to keep up with technological breakthroughs, forcing employees to learn new software all the time. Although they may initially be enthusiastic about learning new applications and technologies, constant requirements for refreshing and updating eventually create frustration and anxiety. Network failure occurs when employees find it difficult to access the Internet in order to carry out an assignment or get across to a client, they often get frustrated. This might stall an online conference or access to some needed information. Another cause of techno stress is computers behaving badly. When the computers do not perform exactly as it is expected to perform, individuals often feel their time is wasted and this can cause stress to build up. Hardware ergonomics occurs when individuals feel some form of discomfort when using the computer which could pose very serious health problems if it is overdone. The need to ensure that a computer work area is set up in the appropriate way will prevent fatigue and stress. Inappropriate and improper training occurs since all employees do not learn the same way. People have different learning styles and what training program works well for some may not work well for others. Some people need hands-on training to learn new technology, while some people only have to read a manual to understand. Techno stress can thus manifest in the workplace as irritable, perfectionistic workers who hold high expectations for the machines with which they work.

\section{Ergonomics}

Ergonomics is the profession of designing machines, tools, and work environments to best accommodate human performance and behaviour, Occupational Safety and Health Administration [70]. It aims to improve the practicality, efficiency, and safety of a person working with a machine or device. When ergonomics is applied correctly in the work environment, discomfort and fatigue are reduced significantly. Thus, ergonomics removes barriers to quality, productivity and safe human performance by fitting products, tasks, and environments to people. 
Along with the proliferation of technology, concerns about the safe and comfortable use of computers have emerged. This study is majorly concerned about Computer Ergonomics, which is the science of adjusting the work environment to fit the body and to make it as comfortable as possible. This is because accountants and auditors, and even most organisations, make use of computer-based technology (which has become indispensable in most offices) to execute office tasks without considering the hazards it could impose on the employees. Hence, since the primary goal of ergonomics is to minimize employee exposure to ergonomic hazards which could lead to illnesses and injuries, this study is intended to help identify basic ergonomic standards and possible hazards which could result if ergonomics are neglected within organisations. Without proper computer set-up and use, there are many injuries that may result. For example, bad posture can cause fatigue, muscle strain, and, in later stages, pain. By identifying ergonomic hazards that can result in an injury or illness, and correcting these hazards, employees can be provided a healthier workplace. Ergonomics therefore attempts to "fit the job to man" rather than "fit the man to the job" or "fit the task to the person and not the person to the task" [43].

Certain administrative controls that can be used effectively are to attain a reasonable level of ergonomics in an organisation include:

\subsection{Identifying Ergonomic Hazards}

Review records of injuries, including repetitive trauma disorders, along with information about the related task or activity and probable causes, workers' complaints of discomfort, high absenteeism, frequent clinic visits. This can be better achieved by identifying and analysing trends or problems related to particular departments, areas, job functions, workstations, etc.

\subsection{Setting up Infrastructures}

Ergonomic programmes should be regarded as part of the general safety programme and should be integrated into the company's occupational safety and health activities. Management must show commitment and give ergonomic improvements equal priority with cost reduction and productivity.

\subsection{Job Enlargement}

Have employees perform more parts of a job rather than one specific task repeatedly.

\subsection{Job Rotation}

Cross-train employees perform other jobs. Rotate employees in jobs that use different groups based on the job description.

\subsection{Work Breaks}

Have employees take frequent short breaks from repetitive tasks throughout the day.

\subsection{Training}

Training provides information for mitigating ergonomic hazards, strategies to improve a workstation layout, and stress-reduction exercises. Training employees ensures that they are informed about the hazards in their work place so that they can actively participate in identifying and controlling exposures. Training of employees is critical to the success of an ergonomics program. Both employees and managers require the knowledge to recognize potential risk factors for injuries and their prevention. The more aware the workers are of ergonomic hazards in their workplace, the more likely they are to work towards reducing injuries.

\section{Ergonomic Hazards}

Office workers are exposed to a number of health risks as a result of ergonomic hazards. Hazard is considered as any working condition which has the potential to affect employee health [59]. Hazards associated with the use of technological devices such as the computer usually occur gradually and often go unnoticed until there is significant discomfort. Some job tasks expose workers to a lot of vibration and noise (for example, the use of generat- 
ing sets in an office environment), eye strain, and repetitive motion. Others might be cases in which machines, tools and the work environment are not designed properly, thereby placing stress on workers. In a study on technostress in the workplace carried out by [30], it was discovered that more than $30 \%$ of employees who work at the computer experience neck and back pain; hand and arm pain, tingling and numbness; and exhaustion. This was corroborated by [58] who discovered that more than 25\% of Europeans experience work-related neckshoulder pain and $15 \%$ experience work-related arm pain as a result of adapting to new technology usage. It was also discovered that the largest increase in back-ache were seen among computing professionals and technicians [58]. Recognizing ergonomic hazards in the workplace is the first step in improving workers' comfort and ultimate output.

Ergonomic hazards can result from sedentary work (involving a lot of sitting and correspondingly little exercise), working with limited or slow network services. Work load in the office divers based on type of task. Regardless of the type of tasks, many office jobs are now dependent on the use of computers in order to execute tasks such as editing or inputting, communication via e-mail and instant messaging, which all requires a worker to spend time at the computer screen.

In the past, communication flow was done in such a way that workers moved away from their desks and interacted with other members of the workforce. However, with the advent of computers, and the increasing use of palm-held devices (e.g. blackberries and androids), screen-dependent workloads have become unavoidable, leading to some notable ergonomic hazards such as:

\subsection{Musculoskeletal Disorders (MSDs)}

Repetitive Strain Injury (RSI) is a commonly-used term for these disorders (European Agency for Safety and Health at Work, 2006).

\subsection{Body Fatigue}

Body fatigue can occur when excessive pressure or other types of demand are placed on employees. All workers experience pressure in their work, but excessive pressure can lead to stress, which can undermine performance, can be costly to employers and can lead to physical and/or mental illness.

\subsection{Visual Fatigue}

Although medical evidence indicates that using computers is not associated with permanent damage to the eyes, some workers may experience temporary visual fatigue. This can lead to impaired visual performance, headaches, and tired, red or sore eyes. These symptoms may be caused by concentrating on the screen for a long time, poor positioning of the computer, flickering screens, inadequate lighting, glare and refection, or poor legibility of paper or screen documents.

\section{Technostress and Performance in Auditing Firms}

The relationship between stress and performance is complex. This is because the findings gained in prior empirical studies regarding the relationship between job stress and job performance are inconsistent. According to [12] individuals under too little stress may not make enough effort to perform at their best levels, while those under too much stress often are unable to concentrate or perform effectively and efficiently. While ICTs have been suggested to positively impact organizational performance [14] [15] they have also been shown to result in stress for employees, leading to such negative organizational consequences as turnover and productivity losses [41] [42]. Specifically, according to [30]-[34] high stress levels experienced by auditors could detrimentally affect job performance. Under highly stressful conditions, auditors experienced greater emotional exhaustion which could affect their approach towards the job [60] found that as the pressure imposed on auditors' increases, auditors' performance in terms of processing accuracy and sampling adequacy declined significantly. This study thus seeks to find out the impact which technostress can have on organisational performance, owing to the different conclusions by different researchers. Furthermore, it is set to find out how individual can make use of technology to the best advantage of individuals and organisations, since [56] asserted that for any technology to be successful, it must be usable, useful, safe, effective and pleasurable. 


\section{Conclusion}

It could be concluded that technological stressors can result in ergonomic hazards, which are detrimental to workers and their places of work due to effect productivity level. It could thus be suggested that improved ICT training and stress management interventions are important processes for enhancing individual and professional well-being in order to prevent technostress and ergonomic hazards.

\section{References}

[1] Szilagyi, A.D. and Wallace, M.J. (1980) Organizational Behavior and Performance. 2nd Edition, Goodyear Publishing Company, Santa Monica.

[2] Blau, G. (1981) An Empirical Investigation of Job Stress, Social Support, Service Length, and Job Strain. Organizational Behavior and Human Performance, 27, 279-302. http://dx.doi.org/10.1016/0030-5073(81)90050-7

[3] Cox T. and Griffiths (1998) The Nature and the Measurement of Work Stress: Theory and Practice: A Practical Er-gonomics Methodology. In: Wilson, J.R. and Corlett, E.N., Eds., Evaluation of Human Work, 2nd Edition, Taylor \& Francis, London.

[4] Cooper, C.L., Dewe, P. and O’Driscoll, M.P. (2001) Organizational Stress: A Review and Critique of Theory, Research, and Applications. Sage, Thousand Oaks.

[5] Alves, M.G.M., Chor, D., Faerstein, E. and Werneck, C.G.L. (2004) Short Version of the “Job Stress Scale”: A Portguese-Language Adaptation. Revista de Saúde Pública, 38, 164- 171.

[6] Rowden, W.R. and Conine, T.C. (2005) The Impact of Workplace Learning on Job Satisfaction in Small US Commercial Banks. Journal of Workplace Learning, 17, 215-230. http://dx.doi.org/10.1108/13665620510597176

[7] Abushaikha, L. and Sheil, E.P. (2006) Labor Stress and Nursing Support: How Do They Relate? Journal of International Women's Studies, 7, 198-208.

[8] Szilagyi Jr., A.D. and Wallace Jr., M.J. (1990) Organizational Behavior and Performance. Scott, Foresman, and Company, Glenview.

[9] Cavanagh, M.E. (1989) What You Don’t Know About Stress. Personnel Journal, 67, 53-59.

[10] Smeltzer, L.R. (1987) The Relationship of Communication to Work Stress. The Journal of Business Communication, 24, 47-57. http://dx.doi.org/10.1177/002194368702400205

[11] Riggio, R.E. (2003) Introduction to Industrial/Organizational Psychology. 4th Edition, Prentice-Hall, Upper Saddle River.

[12] Britton, J., Day, M., Holzworth, A. and Shawcross, M. (2000) Technostress: Real Issues, Real Solutions. University of Denver, USA.

[13] Choo, F. (1995) Auditors’ Judgment Performance under Stress: A Test of the Predicted Relationship by Three Theoretical Models. Journal of Accounting, Auditing \& Finance, 10, 611-641.

[14] Rebele, J.E. and Michaels, R.E. (1990) Independent Auditors’ Role Stress: Antecedent, Outcome, and Moderating Variables. Behavioral Research in Accounting, 2, 124-153.

[15] Goolsby, J.R. (1992) A Theory of Role Stress in Boundary Spanning Positions of Marketing Organizations. Journal of the Academy of Marketing Science, 20, 155-164. http://dx.doi.org/10.1007/BF02723455

[16] Kahn, R.L., Wolfe, D.M., Quinn, R.P., Snoek, J.D. and Rosenthal, R.A. (1964) Organizational Stress: Studies in Role Conflict and Ambiguity. John Wiley \& Sons Inc., Oxford, England.

[17] Gill, A.S., Flaschner, A.B. and Shachar, M. (2006) Mitigating Stress and Burnout by Implementing Transformational-Leadership. International Journal of Contemporary Hospitality Management, 18, 469-481. http://dx.doi.org/10.1108/09596110610681511

[18] De Zoort, F.T. and Lord, A.T. (1997) A Review and Synthesis of Pressure Effects Research in Accounting. Journal of Accounting Literature, 16, 28-86.

[19] Fisher, R.T. (2001) Role Stress, the Type A Behavior Pattern, and External Auditor Job Satisfaction and Performance. Behavioral Research in Accounting, 13, 143-170. http://dx.doi.org/10.2308/bria.2001.13.1.143

[20] Tu, Q., Wang, K. and Shu, Q. (2005) Computer-Related Technostress in China. Communications of the ACM, 48, 7781. http://dx.doi.org/10.1145/1053291.1053323

[21] Tarafdar, M., Ragu-Nathan, B.S., Ragu-Nathan, T.S. and Tu, Q. (2005) Exploring the Impact of Technostress on Productivity. Proceedings of the 36th Annual Meeting of the Decision Science Institute, San Francisco, 19-22 November 2005, 13771-13776.

[22] Tiwari, T., Singh, A.L. and Singh, I.L. (2008) Information Technology-Induced Stress and Human Performance: A 
Critical Review. Journal of the Indian Academy of Applied Psychology, 34, 241-249.

[23] Campbell, M.C., Sheridan, J.B. and Campbell, K.Q. (1988) How Do Accountants Cope with Stress? The Woman CPA, 50, 4-7.

[24] Sweeney, J.T. and Summers, S.L. (2002) The Effect of the Busy Season Workload on Public Accountants' Job Burnout. Behavioral Research in Accounting, 14, 223-245. http://dx.doi.org/10.2308/bria.2002.14.1.223

[25] McDaniel, L.S. (1990) The Effects of Time Pressure and Audit Program Structure on Audit Performance. Journal of Accounting Research, 28, 267-285. http://dx.doi.org/10.2307/2491150

[26] Khosrowpour, M. and Culpan, O. (1990) The Impact of Management Support and Education: Easing the Causality between Change and Stress in Computing Environments. Journal of Educational Technology Systems, 18, 42-53.

[27] Poole, C.E. and Denny, E. (2001) Technological Change in the Workplace: A Statewide Survey of Community College Library and Learning Resources Personnel. College \& Research Libraries, 62, 503-515. http://dx.doi.org/10.5860/crl.62.6.503

[28] Brillhart, P.E. (2004) Technostress in the Workplace: Managing Stress in the Electronic Workplace. Journal of American Academy of Business, Cambridge, 5, 302-307.

[29] Al-Qallaf, C.L. (2006) Librarians and Technology in Academic and Research Libraries in Kuwait: Perceptions and Effects. Libri, 56, 168-179. http://dx.doi.org/10.1515/LIBR.2006.168

[30] Ahuja, M.K. and Thatcher, J.B. (2005) Moving beyond Intentions and towards the Theory of Trying. MIS Quarterly, 29, 427-459.

[31] Mak, B., Sockel, H., Bucholz, J.A. and Webb, M.W. (2010) Technostress and Organization Loyalty of IS \& T Workers -A Path Model. International Journal of Information Processing and Management, 1, 4-17. http://dx.doi.org/10.4156/ijipm.vol1.issue2.1

[32] Tarafdar, M., Tu, Q. and Ragu-Nathan, T.S. (2011) Impact of Technostress on End-User Satisfaction and Performance. Journal of Management Information Systems, 27, 303-334. http://dx.doi.org/10.2753/MIS0742-1222270311

[33] Agboola, A.A. (2011) Towards Reducing Common Ergonomic Hazards and Alleviating Techno-Stress Associated with the Adoption of Information and Communication Technology. International Journal of Innovation in the Digital Economy, 2, 56-65. http://dx.doi.org/10.4018/jide.2011040105

[34] Choi, H.S., Kim, T.G. and Cho, Y.G. (2011) A Study on the Effects of Technostress on Flow and Continuous Use of Smartphone. Cyber Journal of Korean Institute of Information Technology, 8, 175-184. http://dx.doi.org/10.6109/jkiice.2011.15.1.175

[35] Rajput, N., Gupta, M., Kesharwani, S. and Chhabra, N. (2011) Impact of Technostress in Enhancing Human Productivity: An Econometric Study. Global Journal of Enterprise Information System, 3, 5-13.

[36] Schwartz, H. and Davis, S.M. (1981) Matching Corporate Culture and Business Strategy. Organizational Dynamics, 10, 30-48. http://dx.doi.org/10.1016/0090-2616(81)90010-3

[37] Çoklar, A.N. and Sahin, Y.L. (2011) Technostress Levels of Social Network Users Based on ICTs in Turkey. European Journal of Social Sciences, 23, 171-182.

[38] Prabhakaran, A. and Mishra, H.K. (2012) Technological Change in Libraries: The Evolution of Technostress. Researcher World: Journal of Arts, Science \& Commerce, 3, 131-135.

[39] Ayyagari, R. (2012) Impact of Information Overload and Task-Technology Fit on Technostress. Proceedings of the Southern Association for Information Systems Conference, Atlanta, 23-24 March 2012, 18-22.

[40] Tiemo, P.A. and Ofua, J.O. (2010) Technostress: Causes, Symptoms and Coping Strategies among Librarians in University Libraries. Educational Research, 1, 713-720.

[41] Kupersmith, J. (1992) Technostress and the Reference Librarian. Reference Services Review, 20, 7-50. http://dx.doi.org/10.1108/eb049150

[42] Gorman, M. (2001) Technostress and Library Values. Library Journal, 126, 48-50.

[43] Adekunle, P.A., Omoba, R.O. and Tella, A. (2007) Attitudes of Librarians in Selected Nigerian Universities toward the Use of ICT. Library Philosophy and Practice.

[44] Salami, A.O., Ojokuku, R.M. and Ilesanmi, O.A. (2010) Impact of Job Stress on Managers’ Performance. European Journal of Scientific Research, 45, 249-260.

[45] Isiakpona, C. and Adebayo, O. (2011) The Impact of Technostress on Librarians: A Survey of Covenant University Library. The Information Manager, 11, 56-61

[46] Agbu, J.F. and Olubiyi, K.S. (2011) Technostress in the Age of Information Communication Technology: A Case Study of Distance Education. International Research Educational Journals, 2, 1654-1660.

[47] Olalude, O.F. (2013) Work Values, Achievement Motivation and Technostress as Determinants of Job Burnout among 
Library Personnel in Automated Federal University Libraries in Nigeria. Library Philosophy and Practice. http://digitalcommons.unl.edu/libphilprac/919

[48] Ogundele, O.J.K. (2005) Management and Organization: Theory and Behaviour. Molofin Nominees, Lagos.

[49] Sarikwal, L. and Kumar, S. (2010) An International Study of Work Stress with Types of Workers. Proceedings of ASBBS, 17, 142-155.

[50] Ferris, G.R., Frink, D.O., Gilmore, D.C. and Kacmar, K.M. (1994) Understanding as an Antidote for the Dysfunctional Consequences of Organizational Politics as a Stressor. Journal of Applied Social Psychology, 24, 1204-1220. http://dx.doi.org/10.1111/j.1559-1816.1994.tb01551.x

[51] Marks, M.L. and Mirvis, P.H. (1998) Joining Forces: Making One plus One Equal Three in Mergers, Acquisitions and Alliances. Jossey-Bass, San Francisco.

[52] Judge, T.A., Thoresen, C.J., Pucik, V. and Welbourne, T.M. (1999) Managerial Coping with Organizational Change: A Dispositional Perspective. Journal of Applied Psychology, 84, 107-122. http://dx.doi.org/10.1037/0021-9010.84.1.107

[53] Wanberg, C.R. and Banas, J.T. (2000) Predictors and Outcomes of Openness to Changes in a Reorganizing Workplace. Journal of Applied Psychology, 85, 132-142. http://dx.doi.org/10.1037/0021-9010.85.1.132

[54] Friedman, M. and Rosenman, R.H. (1974) Type A Behaviour and Your Heart. Alfred A. Kpnoff, New York.

[55] Kirmeyer, S.L. and Dougherty, T.W. (1988) Workload, Tension and Coping: Moderating Effects of Supervisor Support. Personnel Psychology, 41, 25-139. http://dx.doi.org/10.1111/j.1744-6570.1988.tb00635.x

[56] Payne, R.L., Jabri, M.M. and Pearson, A.W. (1988) On the Importance of Knowing the Affective Meaning of Job Demands. Journal of Organizational Behaviour, 9, 149-158. http://dx.doi.org/10.1002/job.4030090206

[57] Melville, N., Kraemer, K. and Gurbaxani, V. (2004) Information Technology and Organizational Performance: An Integrative Model of IT Business Value. MIS Quarterly, 28, 283-322.

[58] Wade, M. and Hulland, J. (2004) The Resource-Based View and Information Systems Research: Review, Extension, and Suggestions For Future Research. MIS Quarterly, 28, 107-142.

[59] Davis-Millis, N. (1998) Technostress and the Organization-A Manager's Guide to Survival in the Information Age. http://web.mit.edu/ninadm/www/mla.htm

[60] Brod, C. (1984) Technostress: The Human Cost of the Computer Revolution. Addison-Wesley Publishing Company, Reading, USA.

[61] Champion, S. (1988) Technostress: Technology’s Toll. School Library Journal, November 1998, 48-51.

[62] Clark, K. and Kalin, S. (1996) Technostressed Out? How to Cope in the Digital Age. Library Journal, 121, 30-32.

[63] Weil, M.M. and Rosen, L.D. (1997) Technostress: Coping with Technology @Work @Home @Play. John Wiley \& Sons Inc., Hoboken.

[64] Arnetz, B.B. and Wiholm, C. (1997) Technological Stress: Psychophysiological Symptoms in Modern Offices. Journal of Psychosomatic Research, 43, 35-42. http://dx.doi.org/10.1016/S0022-3999(97)00083-4

[65] Leka, S., Griffiths, A. and Cox, T. (2003) Work Organisation and Stress. http://www.who.int/occupational_health/publications/en/oehstress.pdf

[66] Occupational Safety and Health Administration (OSHA) (2011) Ergonomics Concepts. http://www.safetyinfo.com/aa-members/Ergonomics-and-Material-Handling.htm

[67] Shu, Q., Tu, Q. and Wang, K. (2011) The Impact of Computer Self-Efficacy and Technology Dependence on Computer-Related Technostress: A Social Cognitive Theory Perspective. International Journal of Human-Computer Interaction, 27, 923-939. http://dx.doi.org/10.1080/10447318.2011.555313

[68] Smeltzer, L.R. (1987) The Relationship of Communication to Work Stress. The Journal of Business Communication, 24, 47-57. http://dx.doi.org/10.1177/002194368702400205

[69] Sweeney, J.T. and Summers, S.L. (2002) The Effect of the Busy Season Workload on Public Accountants' Job Burnout. Behavioral Research in Accounting, 14, 223-245. http://dx.doi.org/10.2308/bria.2002.14.1.223

[70] Szilagyi, A.D. and Wallace, M.J. (1980) Organizational Behavior and Performance. 2nd Edition, Goodyear Publishing Company, Santa Monica, CA. 